\title{
Controlled Release of Construction Chemicals by Encapsulation
}

\author{
Henning von Daake1, Thomas Ballweg2, Dietmar Stephan ${ }^{1 *}$ \\ ${ }^{1}$ Building Materials and Construction Chemistry, Technische Universität Berlin, Berlin, Germany \\ ${ }^{2}$ Fraunhofer-Institute for Silicate Reasearch ISC, Würzburg, Germany \\ Email: ${ }^{*}$ stephan@tu-berlin.de
}

Received 23 December 2015; accepted 5 March 2016; published 8 March 2016

Copyright (C) 2016 by authors and Scientific Research Publishing Inc.

This work is licensed under the Creative Commons Attribution International License (CC BY). http://creativecommons.org/licenses/by/4.0/

CC) (i) Open Access

\begin{abstract}
Encapsulation and controlled release of active agents is a common practice to improve processing and properties of materials and final products in different industries. Today, a large variety of chemical admixtures are used in construction materials, the performance of which could be improved by a better dosage control. This work presents investigations on the controlled release of encapsulated construction chemicals for future applications in construction materials. The high shear mixing technology was used to produce matrix based encapsulations by agglomeration applied to commercially available construction materials. The agglomeration process was varied by the use of different agitator types, the variation of the agitator speed and the application of additional coating materials. The particle size distribution as well as the particle shape of the produced agglomerates was analyzed by automatic image evolution and scanning electron microscopy. The release behavior of the capsules in aqueous solutions was investigated by UV spectroscopy. The obtained results confirmed a theoretical model for the encapsulation and release of admixtures, which was derived from pharmaceutical drug release concepts and adapted to construction materials. The results indicate that the matrix based encapsulation is a promising technique for future applications in the field of construction materials.
\end{abstract}

\section{Keywords}

Construction Chemicals, Controlled Release, Encapsulation, High Shear Agglomeration

\section{Introduction}

The process ability of cementitious systems is governed by the chemical and mineralogical cement composition, most notably the content and modification of tricalcium aluminate $\left(\mathrm{C}_{3} \mathrm{~A}\right)$, the content of soluble sulfates and the composition of the pore solution during the early stage of the hydration. It is strongly affected by physical para-

*Corresponding author. 
meters like the particle size distribution, the specific surface area and particle-particle interactions as well as the water cement ratio $(\mathrm{w} / \mathrm{c})$. Beyond that, the construction chemical industry provides a wide range of chemical admixtures, e.g. superplasticizers, retarders and accelerators, to improve the fresh and hardened material properties of construction materials. Looking at the mixing process, it is the dosing time of the chemical admixture, which has a significant impact on the fresh material properties due to the rapid hydration reaction of $\mathrm{C}_{3} \mathrm{~A}$ in cement after first contact with water and concurrent surface growth [1]-[5]. The high surface area of the first hydration products often result in an adsorption of chemical admixtures, which are overgrown by later hydration products with the consequence of a sharp loss in performance. With regard to the early hydration process, a delayed release of chemical admixtures would be desirable to enhance the material properties and reduce the amount of chemical admixtures for future applications.

In the fields of pharmacy, nutrition and fertilizer, encapsulation is already a well established practice to generate such controlled release behavior. In general, encapsulation systems can be divided into core@shell particles and matrix based morphologies as illustrated in Figure 1. Core@shell particles are characterized by a liquid or solid core of active material which is covered by a single or a multiple shell around the core. For matrix based encapsulations, the active agent is bound in a solid matrix material which is partially or completely soluble. The drug release of the matrix type encapsulation primarily depends on the properties of the matrix material whereas for core@shell particles several release mechanisms can be applied, e.g. by diffusion, osmotic pressure or dissolution of the membrane [6]-[10]. Normally, solid materials are encapsulated by coating or agglomeration techniques whereas liquid materials are encapsulated by an additional shell, based on different physical or chemical processes. The use of encapsulation systems for the controlled admixture delivery could improve the handling, safety, processing and performance of a wide range of construction materials which are used in civil engineering for future, e.g. dry mix mortars, self-healing agents etc. This could result in an ecological as well as economic benefit for the construction industry.

It was shown by the authors in a previous work that it is possible to produce matrix type encapsulations based on supplementary cementitious materials (SCMs) containing chemical admixtures with delayed release behavior [11]. The obtained results confirm the theory that the production process, the resulting particle size distribution as well as the release behavior of the encapsulated admixtures is mainly influenced by a combination of the materials viscosity and the mixing energy which is introduced in the mixtures during the agglomeration process. As shown in Figure 2(a), a high binder viscosity, due to a combination of low water and high superplasticizer content in the mixture, combined with a low energy input during the agglomeration yields in fly ash coated superplasticizer particles. The dissolution of these encapsulations is retarded by the time span needed for washing off the fly ash coating from the particles surface. With increasing energy input or decreasing binder viscosity during the agglomeration process, a larger proportion of the binder liquid is pressed towards the particle surface resulting in a faster admixture release in aqueous solution as given in Figure 2(b). Nonetheless, the high shear agglomeration technique provides an easy and reproduceable possibility to encapsulate construction chemicals in

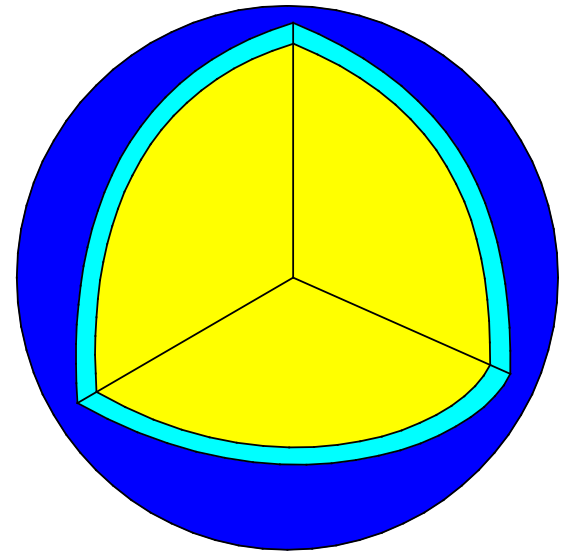

(a)

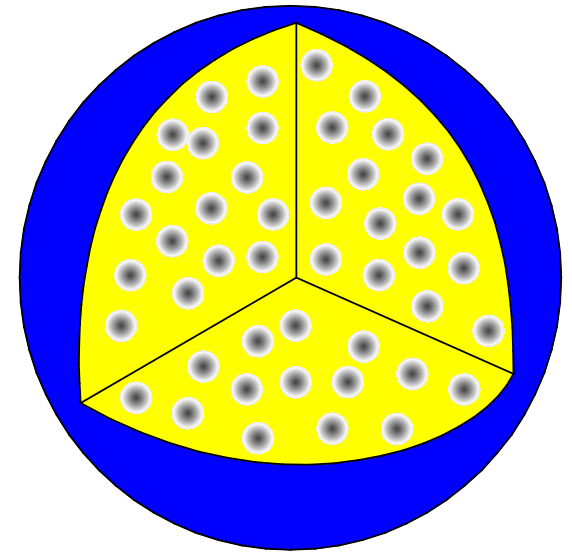

(b)

Figure 1. Illustration of a core@shell particle (a) and a matrix type encapsulation (b), based on $[10]$. 
low binder viscosity and/or low energy input

during the agglomeration high binder viscosity

and/or high energy input

during the agglomeration
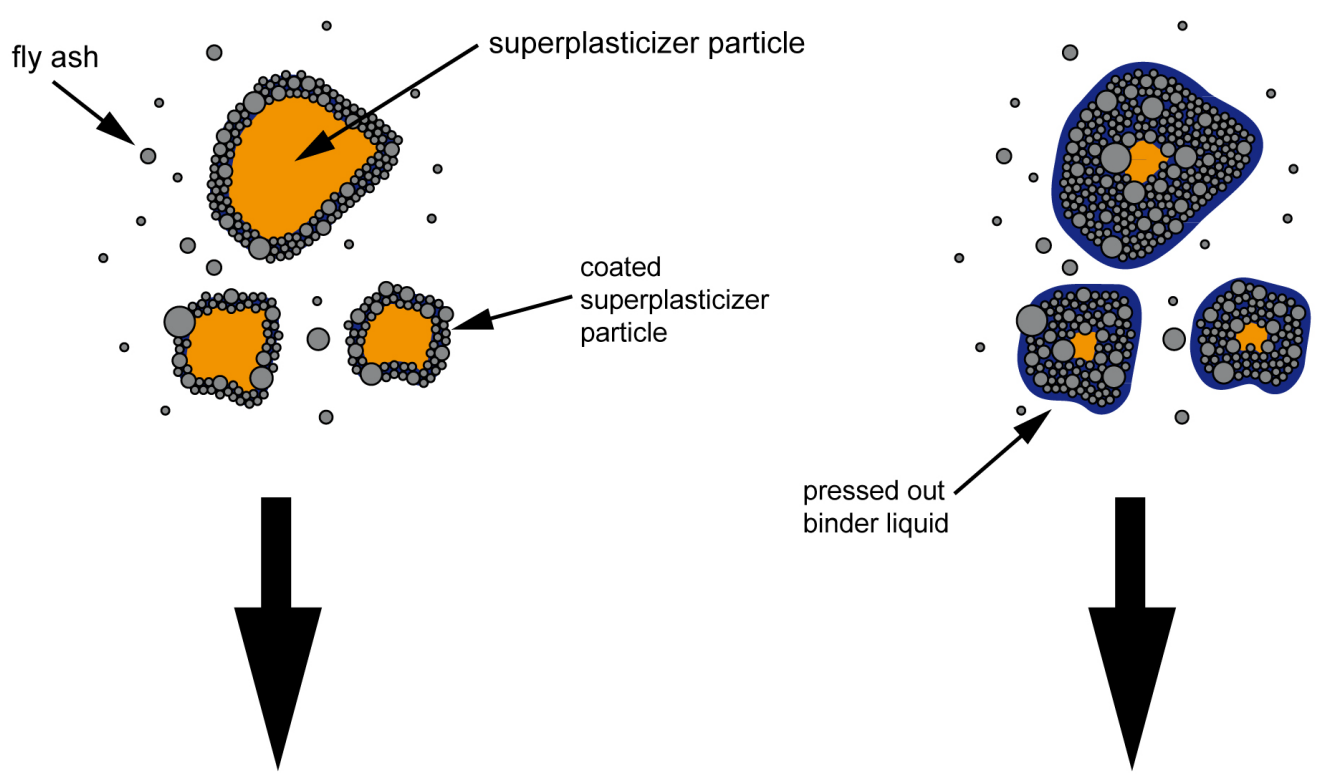

first dissolution of the coating around the particle and subsequent solution of the superplasticizer

direct dissolution of the superplasticizer resp. binder which covers the agglomerates surface

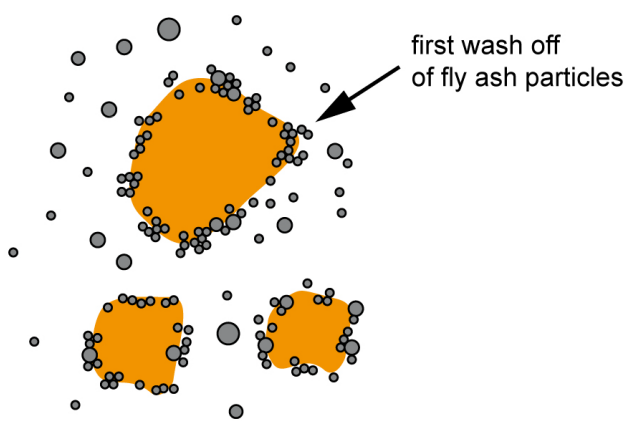

(a)

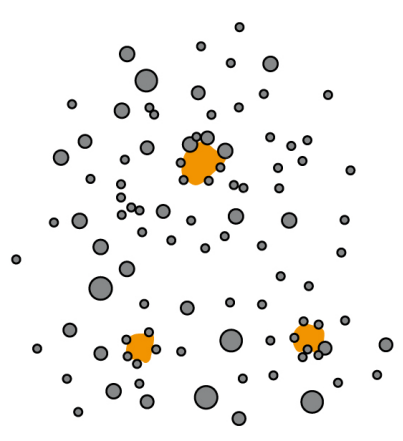

(b)

Figure 2. Encapsulation and dissolution mechanism of the agglomerates depending on the binder viscosity and/or the energy input during the agglomeration process, based on [11].

SCM based agglomerates with retarded release behavior. Due to the maximum mean dissolution time of the agglomerates of $3.6 \mathrm{~min}$, the objective of this research is to retard the release behavior by particle optimization which was done by a variation of the mixing tool used, the tool speed during the agglomeration process as well as by the application of different coating materials.

\section{Materials and Methods}

\subsection{Encapsulation and Coating}

The encapsulation by high shear agglomeration was carried out using a standard fly ash which is commonly used as SCM for mortar and concrete applications and a dry superplasticizer powder based on melamine sulphonate. The particle size distributions and the median particle size $\mathrm{d}_{50}$ of both materials were determined by la- 
ser granulometric analysis (Malvern Mastersizer 2000, UK) and are given in Figure 3(a). Before the agglomeration, fly ash and superplasticizer were homogenized with a combination of $80 / 20$ wt.- $\%$ in a high shear mixer (Eirich R02, Germany) using a star agitator with an impeller speed of $500 \mathrm{rpm}$ for $120 \mathrm{~s}$ and counter-rotating mixing pot on level 1 . The water saturation point of the premixed mixtures was determined by the Puntke test [12], which is a common method in building technology to investigate the water demand of fines.

During the mixing process, $2500 \mathrm{~g}$ dry mixture were agglomerated by the addition of $260 \mathrm{~g}$ of tap water which was sprayed in by a hand pump within $300 \mathrm{~s}$ (vessel speed 1, agitator speed $76 \mathrm{rpm}$ ). After the water addition, all mixtures were agglomerated for $600 \mathrm{~s}$ with a varying agitator type and tool speeds between 440 and $2083 \mathrm{rpm}$. The two used agitator types, a star and a pin agitator, are depicted in Figure 3(b) and Figure 3(c). Due to the equal agitator diameters, the tool speeds of the agitators were comparable. Following, the samples were coated in a second step by the extra addition of an ordinary Portland cement CEM I 42.5 R (5.0 to 7.5 wt.- $\%$ of the production mass) or a silane based dry hydrophobic agent powder (3.0 to $5.0 \mathrm{wt} .-\%$ of the production mass) and further mixing for $60 \mathrm{~s}$ with a tool speed of $178 \mathrm{rpm}$. The mixture compositions of the coated agglomerates are given in Table 1.

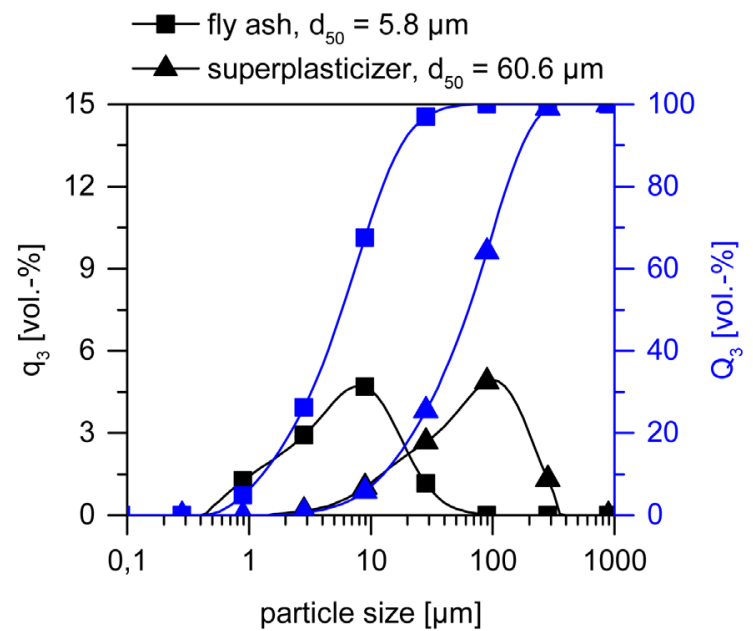

(a)

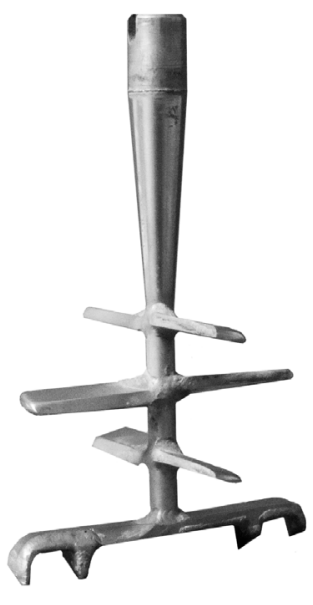

(b)

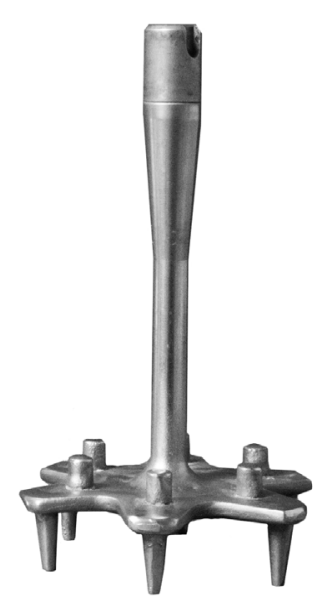

(c)

Figure 3. (a) Particle size distribution of the basic materials, different agitator types used during the agglomeration process; (b) star agitator; (c) pin agitator.

Table 1. Mixture composition of the coated agglomerates.

\begin{tabular}{|c|c|c|c|c|}
\hline Mixture & Mixing tool & Tool speed [rpm] & Coating material & [wt.-\%] \\
\hline M1 & & 660 & - & - \\
\hline M2 & & & - & - \\
\hline C2_5.0 & & & & 5.0 \\
\hline $\mathrm{C} 2 \_7.5$ & Star agitator & 2083 & Cement & 7.5 \\
\hline $\mathrm{H} 2 \_3.0$ & & & Hydronhohic agent & 3.0 \\
\hline H2_5.0 & & & пушіорно0іс agent & 5.0 \\
\hline M3 & & & - & - \\
\hline $\begin{array}{l}\text { C3_5.0 } \\
\text { C3_7.5 }\end{array}$ & Pin agitator & 1902 & Cement & $\begin{array}{l}5.0 \\
7.5\end{array}$ \\
\hline $\begin{array}{l}\text { H3_3.0 } \\
\text { H3 } 5.0\end{array}$ & & & Hydrophobic agent & $\begin{array}{l}3.0 \\
5.0\end{array}$ \\
\hline
\end{tabular}




\subsection{Particle Size Analysis}

The particle size distribution was characterized with the automatic image evolution system Camsizer ${ }^{\circledR}$ (Retsch Technology, Germany) in a particle size range of 0.3 to $30 \mathrm{~mm}$. The analysis yields the particle size distribution, the median particle size $\mathrm{d}_{50}$ and the specific particle surface $\left(S_{v}\right)$ according to Equation (1).

$$
S_{v}=\frac{\text { sum of particle surfaces }\left[\mathrm{m}^{2}\right]}{\text { sum of particle volume }\left[\mathrm{m}^{3}\right]}\left[\mathrm{m}^{-1}\right]
$$

\subsection{Scanning Electron Microscopy (SEM)}

The surface of the agglomerates was investigated by scanning electron microscopy (SEM). To ensure good conductivity conditions during the investigations, the samples were sputtered with platinum. The observations were done with a SEM Zeiss Supra 25 (Carl Zeiss AG, Germany).

\subsection{Admixture Release}

The admixture release behavior of the agglomerates was determined by UV spectroscopy (UV-1650PC, Shimadzu, Japan). The successful determination of the dissolution of melamine based superplasticizers in aqueous solutions is reported by Spanka and Thielen [13] within a wavelength area between 200 and $400 \mathrm{~nm}$. However, the determination in high alkaline solutions like cementitious materials is difficult, since high $\mathrm{pH}$ values enhance the main transmission peak of the UV spectrum of melamine based admixtures at $228 \mathrm{~nm}$ [13]. Due to this, the dissolution behavior of the granules was investigated in deionized water and concurrent mixing with a magnetic stirrer.

To assess fluctuations of superplasticizer concentration of the agglomerates, the admixture content was analyzed before by the loss of ignition up to $1000^{\circ} \mathrm{C}$. In all cases nearly the complete superplasticizer content was found in the produced granules. Furthermore, to evaluate the influence of the agglomerate size on the admixture release behavior, uncoated agglomerates were classified by sieve analysis before the determination of the admixture release.

To evaluate the dissolution behavior of the agglomerates, a Weibull function as given in Equation (2) was fitted to the obtained data from UV spectroscopy, which allows a complete fit of the dissolution rate [14] [15].

$$
W_{t}=\left(1-\mathrm{e}^{-(k \cdot t)^{d}}\right) \cdot 100
$$

with

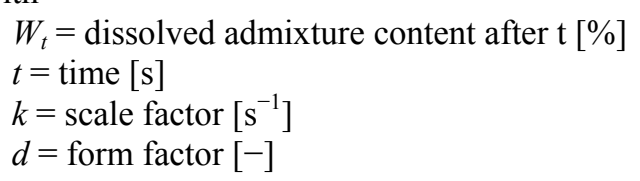

After fitting, the dissolution behavior of the agglomerates was evaluated by the calculation of the mean dissolution time (MDT) which is a common method in pharmacy and medicine since the early 1980s. The MDT (cf. Equation (3) and Figure 4) is defined as the mean time to yield the release of the admixture content [16] [17].

$$
\mathrm{MDT}=\frac{\mathrm{ABC}}{Q_{t}}
$$

with

MDT $=$ mean dissolution time $[\mathrm{min}]$

$\mathrm{ABC}=$ area between the curves $[\mathrm{min} \cdot \%]$

$Q_{t}=$ released admixture content after $\mathrm{t}[\%]$

\section{Results and Discussion}

\subsection{Influence of Tool Type and Tool Speed on the Particle Shape and Admixture Release}

The influence of the tool type and the tool speed on the particle size distribution of the produced agglomerate capsules is shown in Figure 5. Furthermore, the influence of the tool speed on the median particle size $\mathrm{d}_{50}$ and the specific agglomerates surface $S_{v}$ is depicted in Figure 6 . 


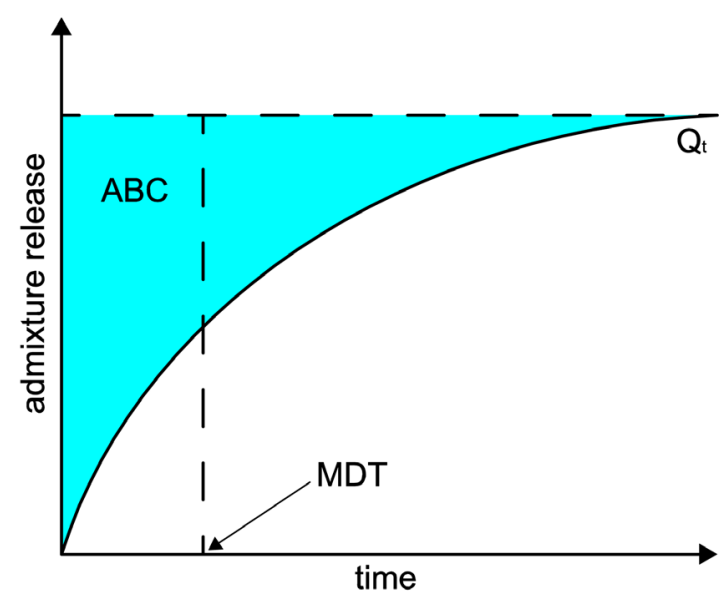

Figure 4. Admixture release and mean dissolution time of matrix based encapsulations, based on [16].
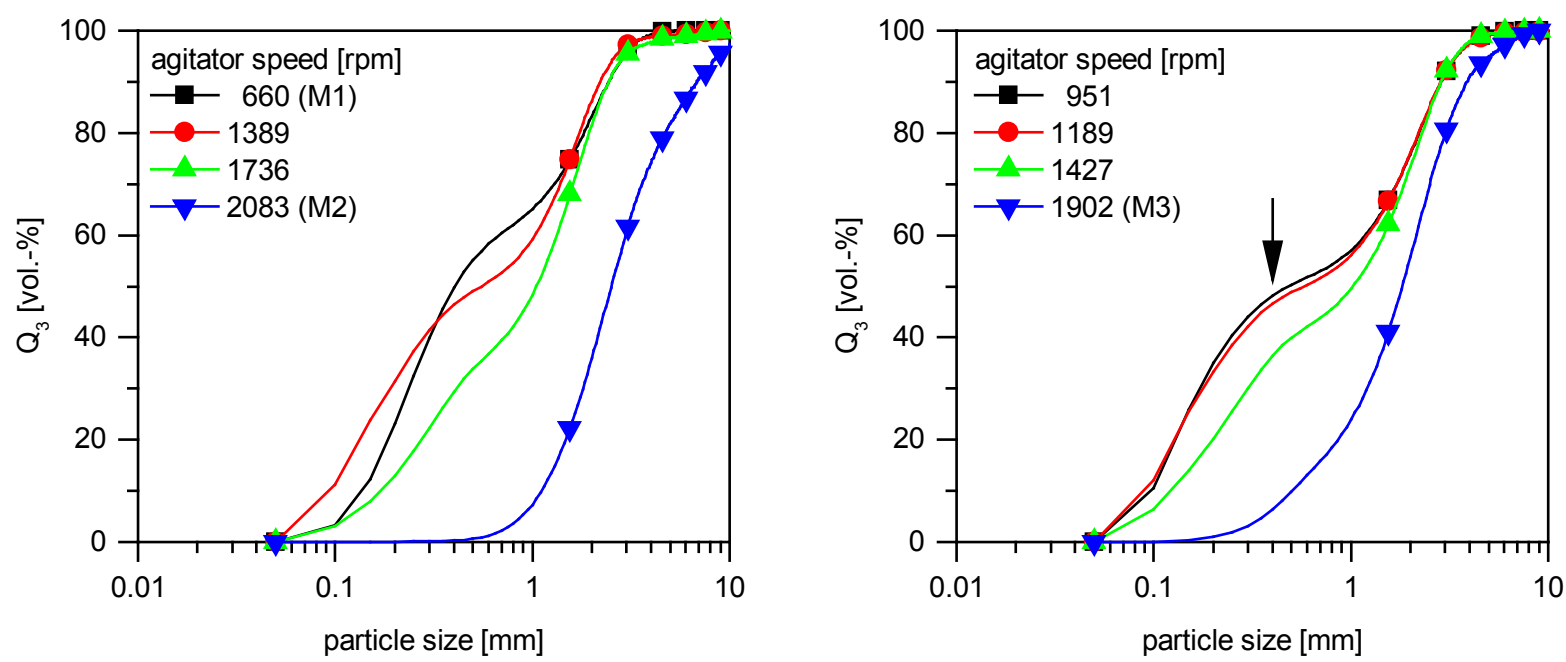

Figure 5. Particle size distributions of selected matrix based capsules agglomerated with the star agitator respectively and the pin agitator.

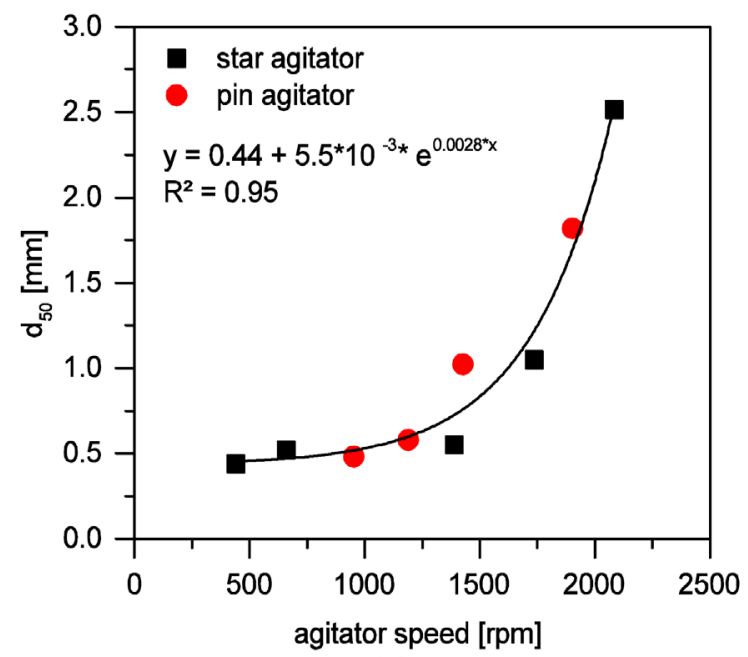

(a)

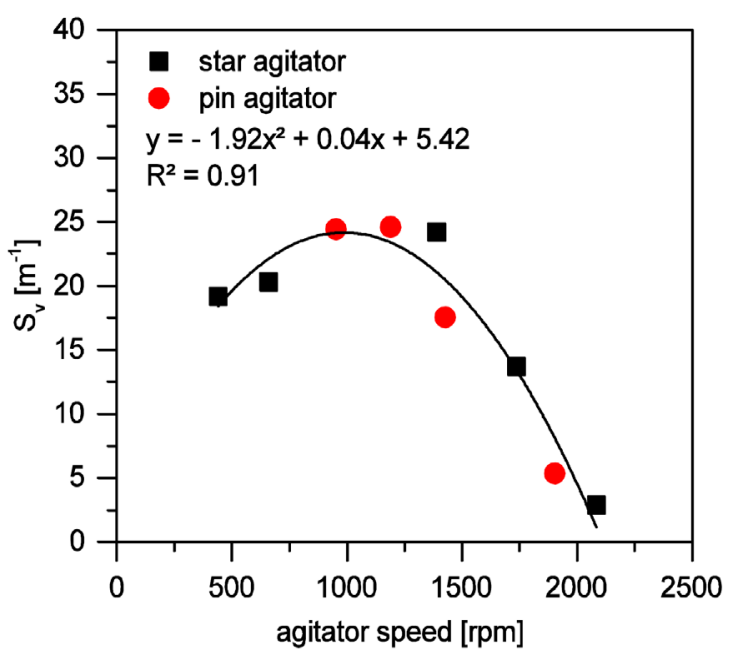

(b)

Figure 6. (a) Median particle size $\mathrm{d}_{50}$ and (b) specific particle surface $S_{v}$ of the produced agglomerates. 
Independent of the agitator type used, a minor fraction of very fine particles below $0.1 \mathrm{~mm}$ was found at tool speeds up to $1736 \mathrm{rpm}$ as given in Figure 5. Probably, these particles are very small agglomerates or a rest of the starting material, which was not agglomerated during the process. The major particle fraction in a range between 0.1 and approx. $2 \mathrm{~mm}$ was mostly influenced by the tool speed. If the materials were mixed with a slow agitator speed of 660 respectively $951 \mathrm{rpm}$, an inhomogeneous slope of the particle size distribution was observed with a peak at a particle size of approx. $0.4 \mathrm{~mm}$ as marked by the arrow in Figure 5(b). With increasing agitator speed the slope of the particle size distribution is more homogeneous due to a continuous growth of the agglomerates. The particle fraction with a size above $2 \mathrm{~mm}$ is comparable for all agglomerates independent of the impeller speed used up to $1736 \mathrm{rpm}$ and independent of the tool type used. With a further increase of the tool speed during the agglomeration process to 2083 respectively 1902 rpm bigger agglomerates with a narrow particle size distribution were obtained.

As depicted in Figure 6(a), the median particle size $\mathrm{d}_{50}$ of the produced agglomerates was nearly constant at $0.5 \mathrm{~mm}$ up to an impeller speed of approx. $1500 \mathrm{rpm}$. Subsequently, it rose up with the increasing impeller speed. A significant influence of the agitator type used was not observed. The particle size of the agglomerates was only influenced by the speed of the mixing tool. Based on the agglomeration model described above, a consolidation of first formed agglomerates takes place with an increasing impeller speed. Due to the consolidation inner water or binder liquid was pressed out of the agglomerates. The moistening of the particles surface facilitates an additional accumulation of fine particles or the bridging of small agglomerates to bigger ones.

The data given in Figure 6(b) indicate that the maximum value of the specific particles surface $S_{v}$ was reached with an impeller speed between 1000 and $1300 \mathrm{rpm}$. With increasing tool speed first agglomerates were formed. Due to the agglomerate formation the specific particle surface $S_{v}$ was increased. However, with a further increase of the tool speed above approx. $1300 \mathrm{rpm}$ the particle surface was decreased. With increasing mixing energy (or tool speed), a consolidation of the formed agglomerates takes place. Due to this consolidation, water and/or binder liquid from the agglomerates core is pressed to the particles surface. This second wetting step facilitates the bridging of small agglomerates to bigger particles accompanied by a decrease of the specific particle surface $S_{v}$.

The dissolution behavior of the particle fractions of the agglomerates M1, M2 and M3 is given in Figure 7(a)-(c). In all cases the dissolution of the agglomerates was well approximated by the Weibull function described above. Figure 7(d) depicts the calculated mean dissolution time MDT with respect to the particle fraction. Comparing the results for the agglomerates M1 and M2 (cf. Figure 7(a) and Figure 7(b)) the dissolution of the admixture was slightly decreased with increasing tool speed. Furthermore, the dissolution was also slightly decreased with increasing particle size, which is observable in the shift of the approximated dissolution functions to later times as given in Figure 7(b). The investigations of the dissolution of the agglomerate M3 in Figure 7(c) lead to similar results. Even if the biggest particle fraction 2.0 to $4.0 \mathrm{~mm}$ yielded a maximum dissolution of approx. $80 \%$, any qualitative differences of the approximated dissolution function were obtained.

Generally, a decrease of the dissolution velocity with increasing particle size can be expected. This tendency could be observed as depicted in Figure 7(d). Furthermore, the MDT of agglomerate M2 was slightly increased compared to agglomerate M1. For agglomerate M3 a slower dissolution velocity of the smaller particles was observed which approached to that of the other agglomerates with increasing particle size. However, the linear regression depicted in Figure 7(d) yields a slope of only 0.17 with a $R^{2}=0.96$. Due to the small gradient angle, it is quite difficult to retard the admixture dissolution of the investigated agglomerates only by an enlargement of the particle size.

The particle shape as well as the particle surface of the fraction 1.0 to $2.0 \mathrm{~mm}$ of the agglomerates M1, M2 and M3 is shown in Figure 8. While agglomerate M1 seems to have a flat particle shape and porous microstructure, agglomerate M2 is characterized by a nodular particle shape and a denser surface microstructure (cf. Figure 8(a) and Figure 8(c)). The more compact appearance of agglomerate M2 compared to agglomerate M1 can be explained by the higher impeller speed which was applied during the agglomeration process leading to an enrichment of the binder in the surface region. This is confirmed by surface analysis at higher magnification as shown in Figure 8(b) and Figure 8(d). Comparing the particles surfaces in Figure 8(b) and Figure 8(d), significant differences are observable. The surface of agglomerate M1 in Figure 8(b) is characterized by the ball-shaped fly ash particles which are loosely glued by interparticle bridges. For agglomerate M2, the primary fly ash particles are completely coated. The glue respective the coating is based on the superplasticizer which was dissolved by the water during the agglomeration and was transported to the surface region during the 


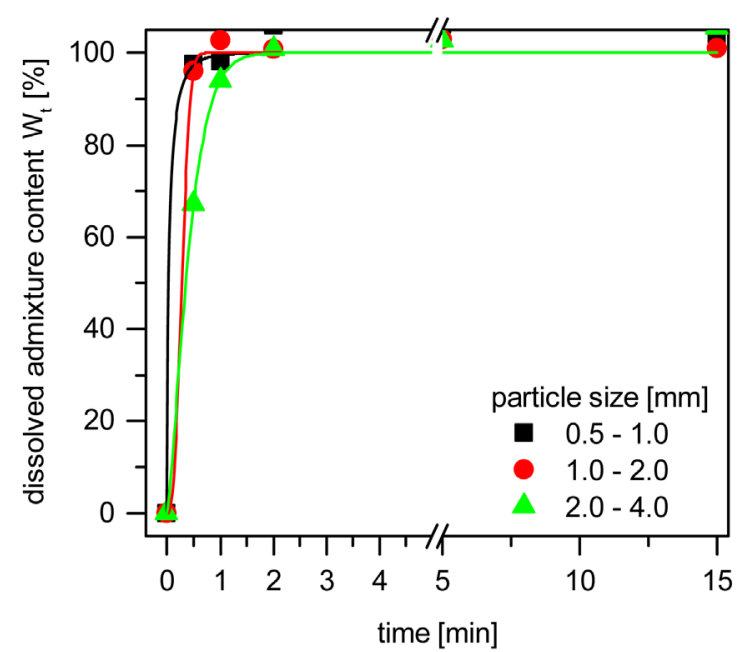

(a)

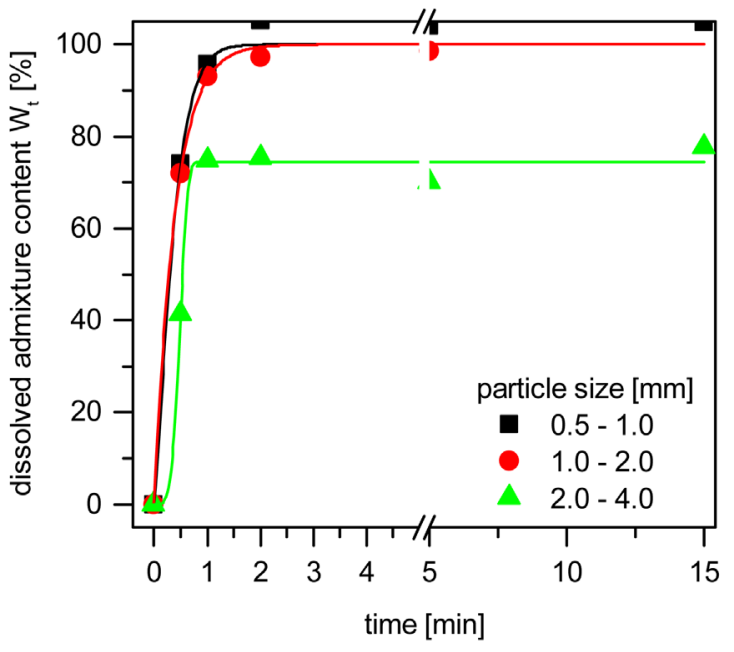

(c)

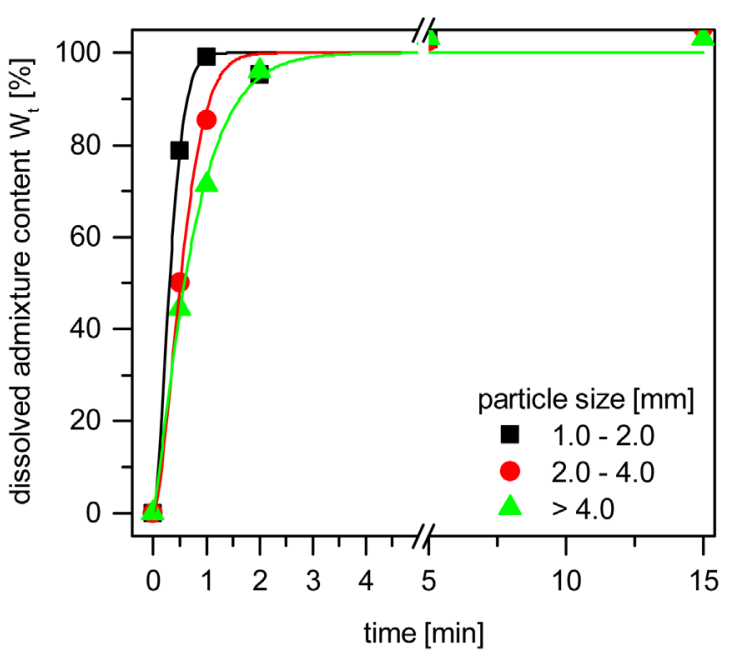

(b)

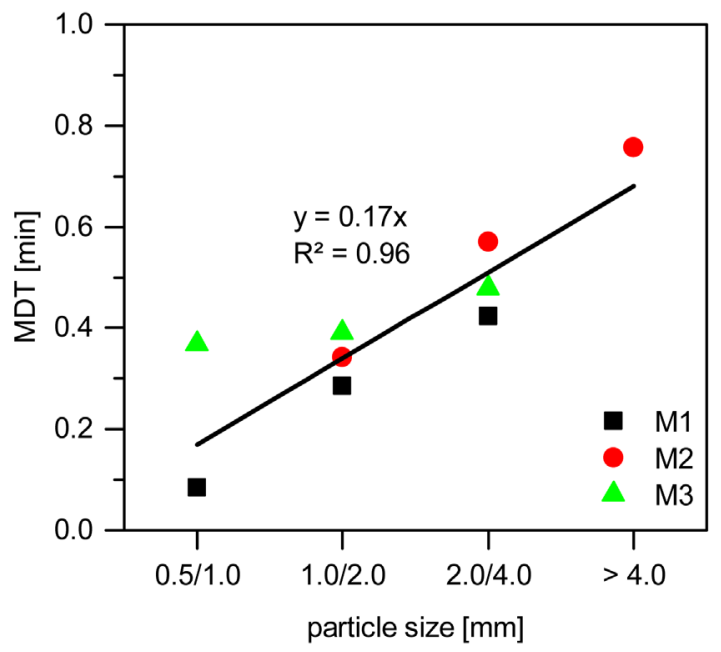

(d)

Figure 7. Dissolution functions of (a) M1; (b) M2; (c) M3 depending on the particle size; (d) correlation between the calculated mean dissolution time MDT and the agglomerate size.

consolidation.

Agglomerate M3 has nearly the same particle shape as agglomerate M2 (cf. Figure 8(e)). However, the surface of this agglomerate was quite different. As can be seen in Figure 8(f), it is characterized by a cover of fly ash particles mixed with a second particle type of different shape. We assume that the later result from superplasticizer which was deformed during the agglomeration. However, presumably due to the lower impeller speed during the agglomeration process, the agglomerates of mixture M3 appear less compact compared to mixture M2. Due to the variation of the impeller used, as well as the slightly decreased impeller speed, agglomerate M3 was less consolidated compared to agglomerate M2. Because of the differences in the compaction, agglomerate M2 is completely covered with superplasticizer whereas such coating could not be observed for agglomerate M3.

\subsection{Influence of the Coating on the Admixture Release}

To further retard the dissolution behavior, the agglomerates were provided with an additional coating consisting of either a cement layer or a dry hydrophobic agent powder. The cement layer should mechanically stabilize the outer shell of the particle to prevent a fast mechanical dissolution. However, the hydrophobic agent should distract the water from the matrix type particle to prevent solving by direct contact with water. The dissolution 

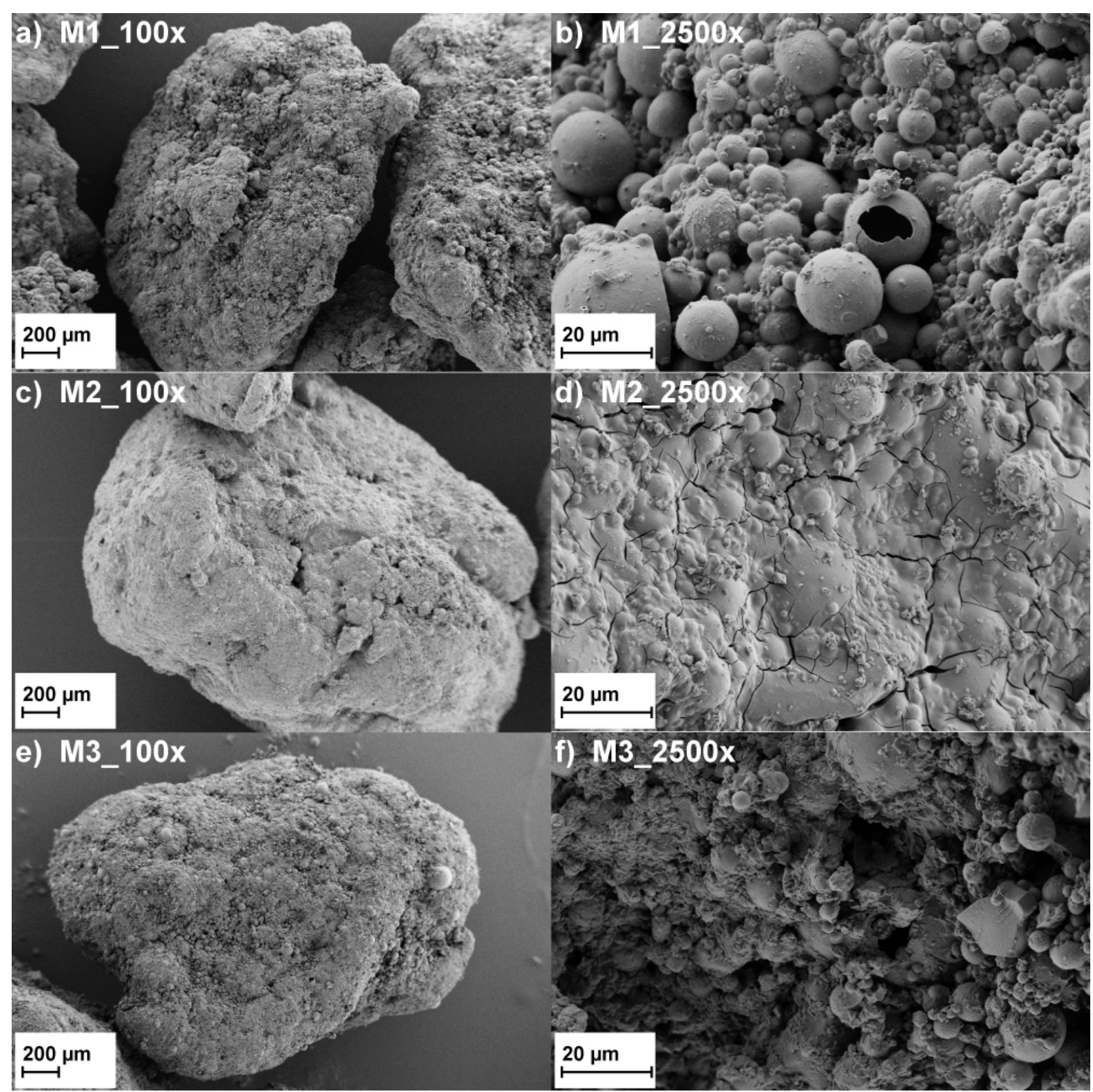

Figure 8. SEM images of classified agglomerates $(1.0-2.0 \mathrm{~mm})$ from mixtures M1, M2 and M3.

behavior in aqueous solution of both modifications is depicted in Figure 9(a) and Figure 9(b). Figure 9(c) depicts the calculated mean dissolution time of the different agglomerates. Looking at the agglomerate types M2 and M3 before coating, the dissolution times MDT of $0.5 \mathrm{~min}$ for M2 and $0.6 \mathrm{~min}$ for M3 are quite comparable. The slight difference results from higher superplasticizer content available on the particles surface. This enhances the dissolution behavior of the admixture and approves the assumption of the model of controlled release described in Section 1.

With the additional cement coating of M2, the dissolution was slightly retarded compared to the uncoated sample independent of the cement content added while the corresponding MDT was slightly decreased (cf. Figure 9(c)). Compared to M2, the retarding effect of the cement coating at agglomerate type M3 was found to be stronger and again independent of the content added. As given in Figure 9(c), the MDT of the uncoated particle M3 was doubled from $0.6 \mathrm{~min}$ to $1.2 \mathrm{~min}$ by the additional cement coating.

A stronger retardation of the admixture dissolution was achieved by a coating based on hydrophobic agents. With this type of layer, an obvious correlation between the amount of the hydrophobic agent and the dissolution 


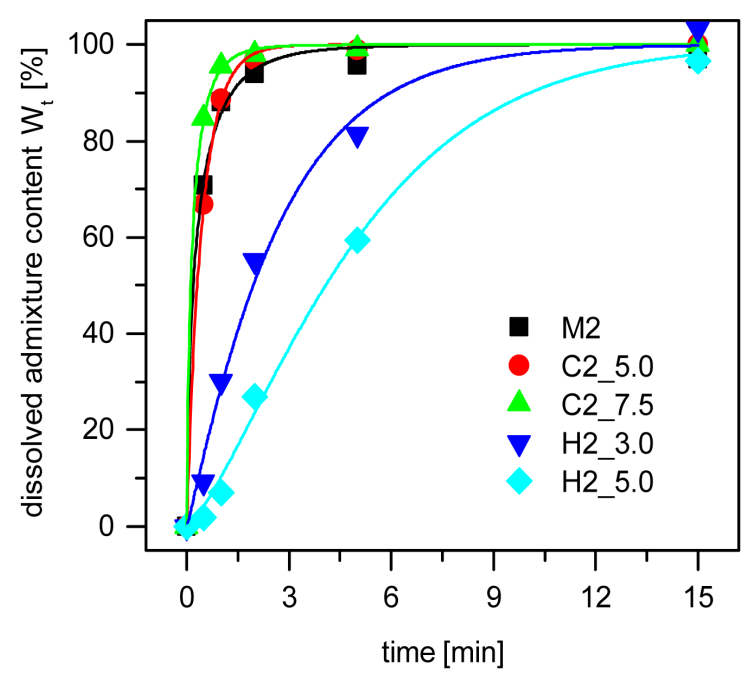

(a)

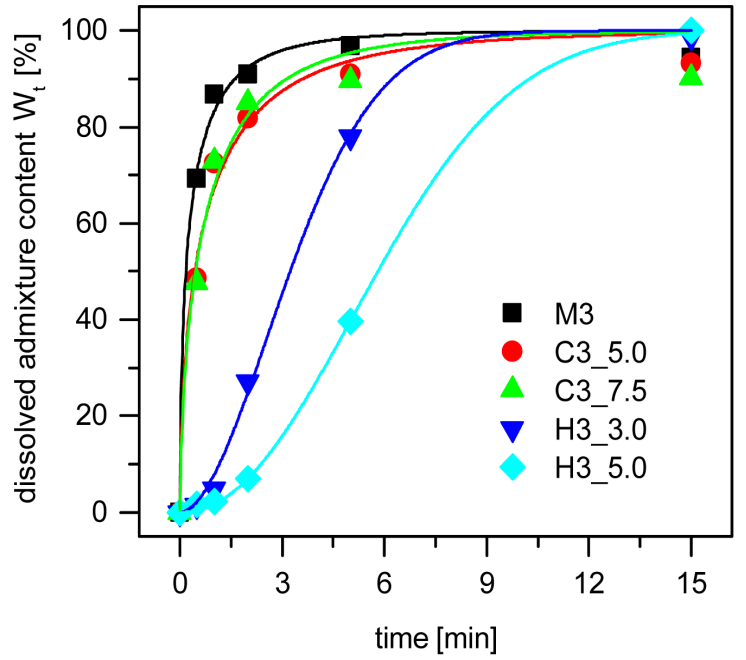

(b)

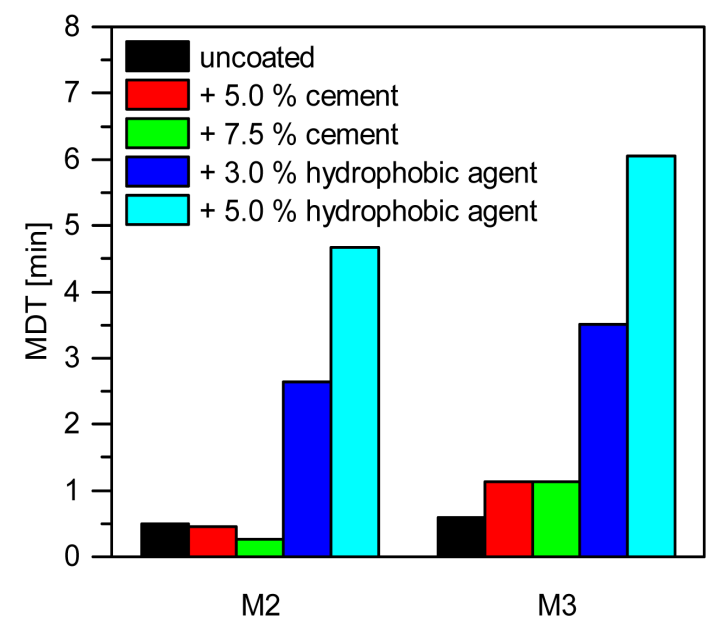

(c)

Figure 9. Dissolution functions of (a) M2 and (b) M3 with different additional surface coatings; (c) calculated mean dissolution times MDT in aquous solution (c).

time could be observed for all agglomerate types investigated. With increasing amount of the hydrophobic agent, the onset of dissolution was continuously shifted towards later time. The corresponding MDTs given in Figure 9(c) confirm the observations. With the addition of the hydrophobic coating, the MDT was significantly extended in all cases with a maximum span up to 6 minutes. This means that the high shear mixing technology in combination with hydrophobic treatment enabled the controlled release of active agents with retardation times in the range of several seconds up to 6 minutes.

SEM pictures of agglomerate type M3 with an additional coating of cement resp. hydrophobic agent reveal characteristic differences in surface morphology in Figure 10. On the one side, the cement coated agglomerate shows a particle surface comparable to the reference mixture without an additional coating. However, additional cement grains of crushed shape are observable at the agglomerates surface with increasing cement content (cf. Figure 10(b) and Figure 10(d)). On the other side, the hydrophobic agent coated particles are characterized by a thin cover at the surface (cf. Figure 10(e) and Figure 10(g)). The SEM pictures of the agglomerates surface in Figure 10(f) and Figure 10(h) depict that the characteristic agglomerates surface is completely different to that of the uncoated agglomerate M3 in Figure 8(f). This observation confirms the effect of the additional coating of the hydrophobic agent which results in the delayed release of the admixture as presented in Figure 9(c). 

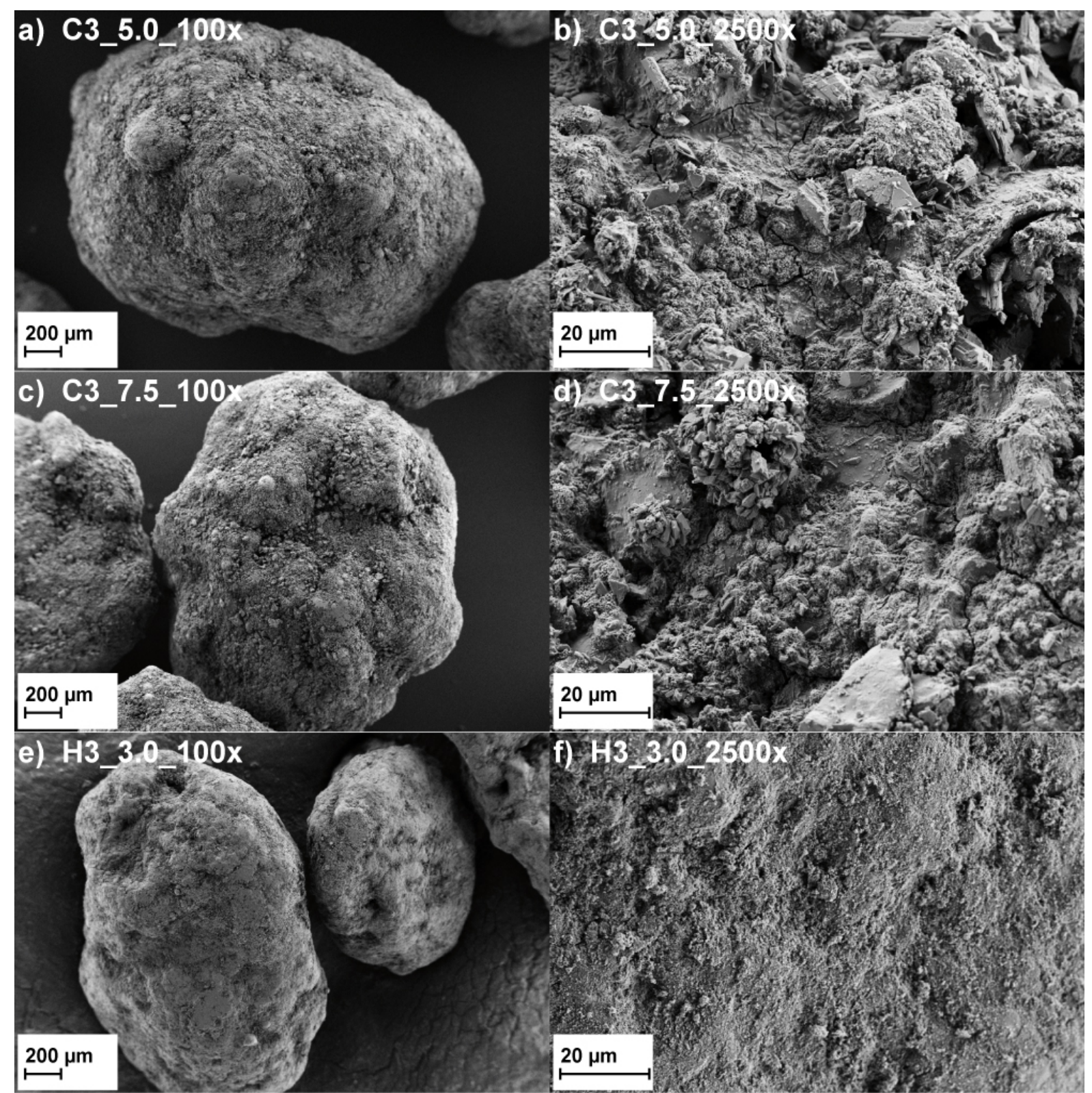

g) $13 \_5.0 \quad 100 x$

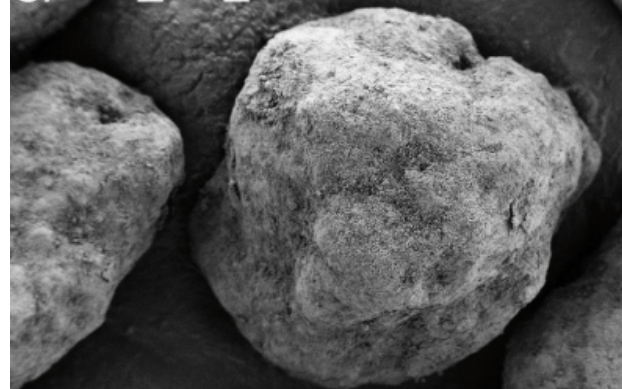

$200 \mu \mathrm{m}$

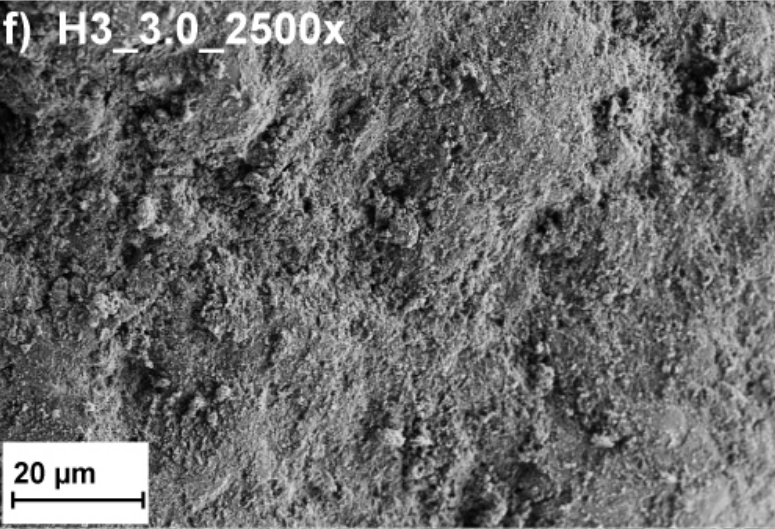

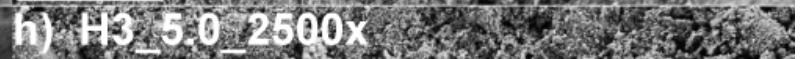

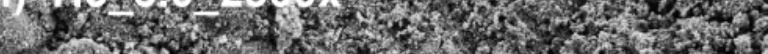
130 . W.

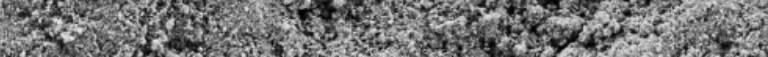
17.2.

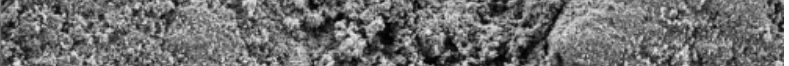

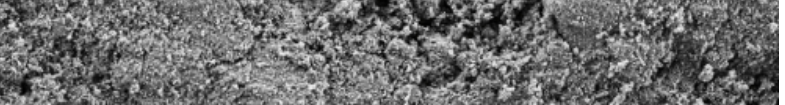

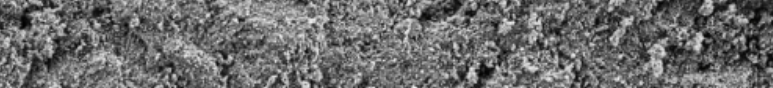
$\stackrel{200 \mu \mathrm{m}}{\longmapsto}$

$20 \mu \mathrm{m}$

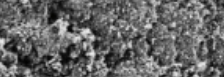

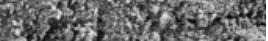

Figure 10. SEM images of classified agglomerates $(1.0-2.0 \mathrm{~mm})$ from mixtures M2 and M3 with additional coating of cement (a)-(d) or hydrophobic agent (e)-(h). 


\section{Conclusion}

The encapsulation of construction chemicals is a promising technique to enhance the properties of different construction materials. Based on first matrix based granules, which were produced by the use of the high shear agglomeration technique, a spectrum of controlled release profiles of the admixture was realized. This was done by a variation of the mixing tool used, the tool speed during the agglomeration process as well as by the application of different coating materials. The relevant parameters were identified as follows:

- The release behavior of the encapsulated admixture was mostly influenced by the tool speed, which was applied during the agglomeration process. In contrast, the tool type used had no significant influence on the dissolution of the agglomerates in water.

- An influence of the particle size on the admixture release was also observed due to the varying specific surface of the particles. However, this effect was too small to retard the admixture release significantly.

- Furthermore, an additional coating based on cement and a dry hydrophobic agent powder proved to be a powerful instrument to significantly prolong the dissolution time of the agglomerates. Comparing both coating materials, the hydrophobic agent yielded better results. The mean dissolution time of the agglomerates could be enhanced from approx. $0.6 \mathrm{~min}$ for the uncoated particle to approx. $6.0 \mathrm{~min}$ for the particle coated with the hydrophobic agent.

The present results confirm a model for the encapsulation of construction chemicals with later delayed release behavior, which is reported in a former publication. Future research will focus on the possible application of the matrix based encapsulation of construction chemicals in construction materials like dry mix mortars.

\section{Acknowledgements}

The authors would like to thank Sika Deutschland GmbH and BauMineral GmbH for the supply of the raw materials and the Department of Engineering Geology at Technische Universität Berlin for support with the particle size analysis. The investigations were funded by the German Federal Ministry of Education and Research (BMBF) in the project "Encapsulation of construction chemicals (VIP project 03V0320)".

\section{References}

[1] Hanehara, S. and Yamada, K. (2008) Rheology and Early Age Properties of Cement Systems. Cement and Concrete Research, 38, 175-195. http://www.sciencedirect.com/science/article/pii/S0008884607002189 http://dx.doi.org/10.1016/j.cemconres.2007.09.006

[2] Flatt, R.J. and Houst, Y.F. (2001) A Simplified View on Chemical Effects Perturbing the Action of Superplasticizers. Cement and Concrete Research, 31, 1169-1176. http://www.sciencedirect.com/science/article/pii/S0008884601005348 http://dx.doi.org/10.1016/s0008-8846(01)00534-8

[3] Aitcin, P.-C., Jolicoeur, C. and MacGregor, J.G. (1994) Superplasticizers: How They Work and Why They Occasionally Don't. Concrete International, 16, 45-52.

[4] Banfill, P. (2011) Additive Effects in the Rheology of Fresh Concrete Containing Water-Reducing Admixtures. Construction and Building Materials, 25, 2955-2960. http://dx.doi.org/10.1016/j.conbuildmat.2010.12.001 http://www.sciencedirect.com/science/article/pii/S0950061810006781

[5] Plank, J., Dai, Z., Zouaoui, N. and Vlad, D. (2006) Intercalation of Polycarboxylate Superplasticizers in $\mathrm{C}_{3}$ A. 8th CANMET/ACI International Conference on Superplasticizers and Other Chemical Admixtures in Concrete, Sorrento, 201-214.

[6] Umer, H., Nigam, H., Tamboli, A.M. and Nainar, M.S.M. (2011) Microencapsulation: Process, Techniques and Applications. International Journal of Research in Pharmaceutical and Biomedical Sciences, 2, 474-481.

[7] Nedovic, V., Kalusevic, A., Manojlovic, V., Levic, S. and Bugarski, B. (2011) An Overview of Encapsulation Technologies for Food Applications. Procedia Food Science, 1, 1806-1815. http://www.sciencedirect.com/science/article/pii/S2211601X11002665

[8] Anandharamakrishnan, C. (2014) Techniques for Nanoencapsulation of Food Ingredients. Springer, New York. http://dx.doi.org/10.1007/978-1-4614-9387-7

[9] Ozturk, A.G., Ozturk, S.S., Palsson, B.O., Wheatley, T.A. and Dressman, J.B. (1990) Mechanism of Release from Pellets Coated with an Ethylcellulose-Based Film. Journal of Controlled Release, 14, 203-213. http://www.sciencedirect.com/science/article/pii/016836599090160U http://dx.doi.org/10.1016/0168-3659(90)90160-U 
[10] Staff, R., Holtze, C. and Koltzenburg, S. (2015) Industrietrend: Mikroverkapselung. Nachrichten aus der Chemie, 63, 339.

[11] von Daake, H., Stascheit, R. and Stephan, D. (2016) Matrix Based Encapsulation of Construction Chemicals Using High Shear Agglomeration. Chemical Engineering \& Technology. http://onlinelibrary.wiley.com/woll/doi/10.1002/ceat.201500598/abstract

[12] Puntke, W. (2002) Wasseranspruch von feinen Kornhaufwerken. Beton, 52, 242-248.

[13] Spanka, G. and Thielen, G. (1995) Investigation into the Detection of Plasticizing Concrete Admixtures and into Their Sorption and Elution Behavior. Beton, 45, 320-327.

[14] Kosmidis, K., Argyrakis, P. and Macheras, P. (2003) Fractal Kinetics in Drug Release from Finite Fractal Matrices. Journal of Chemical Physics, 119, 6373-6377. http://dx.doi.org/10.1063/1.1603731

[15] Heinrich, J., Chalabala, M. and Rak, J. (1986) Auflösungskurve und Weibull-Funktion. Acta Pharmaceutica Technologica, 32, 94-96.

[16] Knop, K. (1999) Wirkstofffreisetzung aus festen Arzneiformen—Prüfmethoden, Auswertung, Einflu $\beta$ parameter. Pharmazie in Unserer Zeit, 28, 301-308. http://dx.doi.org/10.1002/pauz.19990280607

[17] Voegele, D., Brockmeier, D., von Hattingberg, H.M. and Lippold, B.C. (1983) Die mittlere Auflösezeit—Ein Parameter zur Prüfung von Liberationsbedingungen auf Vergleichbarkeit. Acta Pharmaceutica Technologica, 29, 167-174. 